\title{
X-linked intellectual disability, Stoll type
}

INSERM

\section{Source}

INSERM. (1999). Orphanet: an online rare disease and orphan drug data base. $\underline{X \text {-linked }}$ intellectual disability, Stoll type. ORPHA:85326

X-linked intellectual disability, Stoll type is characterised by intellectual deficit, short stature and characteristic facies (hypertelorism, prominent forehead, frontal bossing, a broad nasal tip and anteverted nares). It has been described in four males from three generations of the same family. Two females from this family also displayed intellectual deficit and the characteristic facies. Transmission is X-linked. 